\title{
The Effect of the Work-Life Interface on Insomnia: A Longitudinal Analysis of Male and Female Employees in Switzerland
}

\author{
Mario Lucchini* and Egidio Riva*
}

Abstract: This study draws on the Swiss Household Panel and employs specific panel data methods to investigate whether work-life conflict - decomposed into time-, and strain- based conflicts - and lack of recovery during off-job time (i.e. psychological detachment from work) cause insomnia. The findings indicate that, when adequately accounting for individual heterogeneity and the relative importance of multiple causal factors, recovery and recuperation processes appear crucial to the experience of insomnia, while the significance of perceived work-life conflict recede, for both men and women.

Keywords: work-life interface, insomnia, gender, structural path dependence

\section{Les effets de la relation travail-vie personnelle sur l'insomnie : une analyse longitudinale des employées et employés en Suisse}

Résumé: Cette étude s'appuie sur les résultats du Panel suisse de ménages et emploie des méthodes spécifiques pour l'analyse des données du panel pour déterminer si les conflits travail-vie personnelle - décomposés en conflits liés au temps ou à la pression professionnelle - et le (manque de) détachement psychologique du travail provoquent l'insomnie. Les résultats indiquent que, lorsque l'hétérogénéité individuelle et l'importance relative de facteurs multiples de causalité sont correctement pondérées, le processus de récupération émerge comme essentiel à l'expérience de l'insomnie et la tension perçue entre le travail et la vie personnelle s'atténue pour hommes et femmes.

Mots-clés: conciliation travail-vie personnelle, insomnie, le sexe, dépendance de trajectoire structurelle

\section{Der Effekt der Work-Life Balance auf Schlaflosigkeit: eine Längsschnittanalyse von männlichen und weiblichen Angestellten in der Schweiz}

Zusammenfassung: Die Studie basiert auf dem Schweizer Haushalt-Panel und verwendet spezielle Erhebungsmethoden um herauszufinden, ob der Konflikt von Arbeit und Privatleben - sich unterteilend in zeitliche und belastungsbedingte Konflikte - sowie der Mangel an psychologischer Distanz von der Arbeit Schwierigkeiten beim Einschlafen und Schlaflosigkeit hervorruft. Beurteilt man die individuellen Verschiedenheiten und relativen Bedeutungen verschiedener Faktoren lässt sich vermuten, dass Genesungs- und Erholungsprozesse von zentraler Bedeutung für die Erfahrung von Schlafstörungen sind, für Männer und Frauen.

Schlüsselwörter: Vereinbarkeit von Arbeit und Privatleben, Geschlecht, strukturelle Pfadabhängigkeit

* Università degli Studi di Milano-Bicocca, Department of Sociology and Social Research, I-20126 Milano,mario.lucchini@unimib.it and egidio.riva@unimib.it 
Increasing attention has been paid to the potential effects of the work-life interface on health and well-being (for a review see, e. g., Allen et al. 2000; Frone 2003; Gisler et al. 2018; Greenhaus et al. 2006; Grzywacz 2016). In particular, a mounting body of evidence has linked difficulties in combining paid work, family, and other significant domains of life to sleep problems (Buxton et al. 2016; Crain et al. 2014; Lallukka et al. 2010; 2014; Sekine et al. 2006; Sonnentag et al. 2010).

Insomnia, which is generally defined as the difficulty initiating or maintaining sleep, is a prevalent concern in both the workforce and the general population (see, e. g. Magee et al. 2018; Ohayon 2002). It is caused by a wide range of factors, including genetic, psychological, environmental, social, and behavioural. Based on their role, these causal factors can be categorized as predisposing, precipitating or perpetuating (Spielman 1986). More in detail, according to the so-called 3P behavioural model (see also Spielman et al. 1987), anyone has a unique predisposition to insomnia, depending on specific biological, cognitive, and behavioural mechanisms, and insomnia generally occurs when such predisposition interacts with exposure to one or more precipitating factors. Precipitating factors comprise medical conditions, psychiatric disorders, stressful events, interpersonal conflicts and environmental variables (for a critical review of models of insomnia, see, e. g. Perlis et al. 2011). Once insomnia recurs, individuals may make (maladaptive) corrective behavioural and/or cognitive changes in trying to compensate for or cope with sleeplessness. For instance, they may extend bedtime in the evening or in the morning, practice non-sleep activities in the bedroom, stay in bed while awake at night. These are perpetuating factors that sustain rather than ameliorate sleep disturbance.

Within this heuristic framework, the experiences of the work-life interface can be viewed as precipitating factors that may trigger insomnia. Indeed, work and non-work domains may interfere with each other and eventually result in attitudes, psychological conditions and behaviours, which impact the ability to get enough sleep quantity and/or quality (Buxton et al. 2016; Crain et al. 2014; Lallukka et al. 2010; 2014; Sekine et al. 2006). In this respect, past research in the field has posited and empirically proved that resources, namely time and energy, are crucial factors linking the work-life interface and the sleep experience (for a review see, e.g. Crain et al. 2018). For instance, work-family conflict theory (Greenhaus and Beutell, 1985) proposes that, due to competing demands for workers' finite resources, negative spillover either from work to family or from family to work (such as lack of time and distress) may impede effective functioning in other life domains. Analogously, several studies have demonstrated that the psychological component of disconnecting mentally from work during off-job time (Etzion et al. 1998; Fritz and Sonnentag 2006) is quite relevant for health and well-being when individuals are threatened 
with resource loss (e. g. Barnes et al. 2012; Berkman et al. 2015; Kalimo et al. 2000; Sonnentag 2001; Sonnentag et al. 2010).

Even if literature investigating the impact of the work-life interface on health outcomes, including sleep quality and quantity, has recently flourished, a few gaps still need to be filled. In this regard, Grzywacz (2016) has called for further research that could test alternative theoretical frameworks and hypotheses and advance methods. Indeed, the social and psychological mechanisms by which different experiences of the work-life interface affect health outcomes, including sleep, still need to be clarified (Edwards and Rothbard 2000). Competing hypotheses may be formulated based on different theoretical perspectives (Allen and Eby 2016; Shockley et al. 2018). Yet, to date, primary explanations of the reasons why the work-life interface may impair sleep rely on the strain hypothesis (i. e., combing different life domains is straining) and use the work-family conflict construct (Greenhaus and Beutell 1985). Therefore, domains other than work and family are generally overlooked and so is the explanatory power of different items. Besides, most available studies in the work-family literature have drawn on cross-sectional data (for a review see, e.g., Gisler et al. 2018). Hence, as Grzywacz (2016) underlined, these studies have failed to consider the time course of a specific health outcome as well as the progression of the condition. Therefore, they could not prove the existence or determine the magnitude of the causal effects of the work-life interface. Some longitudinal evidence on sleep problems has emerged (e.g., Berkman et al. 2015; Jacobsen et al. 2014; Vedaa et al. 2016). However, to the best of our knowledge, a large part of that specific literature has not considered the concurrent effect of baseline sleep problems (some notable exceptions are, for instance, Jacobsen et al. 2014; Lallukka et al. 2014; Moen et al. 2013) or has not fully accounted for key relevant biological and psychological determinants of sleep (Knutson 2013). Accordingly, the magnitude of the effect of the work-life interface on sleep disturbances is likely to be overstated.

Following Crain and colleagues (2018), who have contended that work and non-work affect sleep through underlying resource mechanisms (i. e. human energy and time), we use data of the Swiss Household panel (Wave 2004 to Wave 2016) and investigate whether the lack of psychological detachment from work (Etzion et al. 1998; Fritz and Sonnentag 2006) and work-life conflict (Greenhaus and Beutell 1985) cause insomnia. In particular, given the frame of reference adopted in this study and due to data availability, we restrained the focus of this study on two forms of work-life conflict: i) time-based conflict, which is experienced when time demands in one domain/role make it difficult to participate in another domain/ role; ii) strain-based conflict, which arises when strain symptoms in one domain/role affect performance in another domain/role (Greenhaus and Beutell 1985). Current literature has indicated gender differences in the risk of developing insomnia (e. g., Knutson 2013; Ohayon 2002) and gender-specific effects of work-life interface on health, well-being, and sleep-related outcomes (e.g., Hammig and Bauer 2009; 
Lallukka et al. 2010; Magee et al. 2018; Maume et al. 2010; Sekine et al. 2006). Accordingly, analyses are stratified by gender.

We believe that this article may contribute to the literature in the field as follows. Building on Grzywacz (2016), we designed a study that could test the power of the strain hypothesis relative to the psychological detachment hypothesis (Etzion et al. 1998; Fritz and Sonnentag 2006). We tested the strain hypothesis by using two items that measure conflict between work and non-work domains, thus allowing us to examine more than just work and family life. Furthermore, longitudinal data analyses - namely fixed effects models estimating the effect of intra-individual change in the independent variables on insomnia - are useful in addressing the challenges involved in drawing causal inferences from non-experimental data and tackle a fundamental problem, i. e. the so-called unobserved heterogeneity or omitted variable bias. Finally, to disentangle the effects of true state dependence and individual heterogeneity (Heckman 1981) on insomnia - and therefore take into account, in addition to potential sociodemographic determinants, primary genetic and psychological factors involved in insomnia - we used the Mundlak (1978) and Chamberlain (1982) method and estimated the extent to which baseline sleep determined current sleep patterns after controlling for a wide set of observed and unobserved individual characteristics.

\section{Theoretical background and research propositions}

Crain, Brossoit and Fisher (2018) have recently proposed a novel and integrated theoretical model, in which two types of resources are specifically considered when investigating the associations among work, non-work and sleep: time and "human energy", which is an umbrella construct encompassing physical and mental energy, and feelings of energetic activation (Quinn et al. 2012). These resources are supposed to intervene in the relationship between the work-life interface and sleep as follows. Time is expected to affect both sleep quantity and quality. On the one hand, when finite time resources are primarily allocated to work and non-work experiences, the amount of time available for sleep is probably reduced and lost. However, when people cannot devote the sufficient amounts of time to their work or non-work roles, they may have to change their sleep schedule (not necessarily to diminish sleep time in exchange for work and family time) in order to fulfil their duties and obligations without delay. Nonetheless, forced adjustments to the circadian processes, i. e. those regulating the sleep-wake cycle, may prevent individuals from falling asleep at their preferred or optimal times and therefore exacerbate sleep problems, such as insomnia. Turning to human energy, primary types of resources may be depleted in the work and non-work domains as a result of physical and cognitive activities, which, in turn, could affect sleep quality and quantity by either facilitating or impairing sleep. For 
instance, fatigue can possibly lead to more sleep time as part of the physiological process (i. e. homeostasis) that enables the organism to preserve and restore physical or cognitive energy. On the contrary, pre-sleep cognitive hyperarousal has a potentially disruptive effect on sleep, in terms of difficulty initiating and/or maintaining sleep (for a review see, e.g., Kalmbach et al. 2018), even though some evidence suggests that work-related rumination or emotional reactivity may also predict positive mood and emotions potentially leading to better sleep quality (e. g. Cropley and Zijlstra 2011; Meier et al. 2016).

Building on Crain, Brossoit and Fisher (2018), conflict between multiple life domains (Greenhaus and Beutell 1985) and failure to detach from work during off-job hours could deplete time and human energy and have harmful effect on sleep and contribute to cause insomnia (see, e. g., Gisler et al. 2018). Accordingly, we may anticipate that:

Hp. 1: Time-based conflict causes insomnia

Hp. 2: Strain-based conflict causes insomnia

Hp. 3: Lack of psychological detachment from work results in insomnia

Although work-life issues are likely to affect sleep-related outcomes, it is reasonable to expect that, after controlling for pertinent work and family-related antecedents of both work-family conflict and insomnia, including baseline sleep, their magnitude of the effect is small. Thus, while testing alternative theoretical hypotheses (Grzywacz, 2016) and discussing each of the resource mechanisms simultaneously in a single model (Crain et al. 2018), we may gain some further insights into which aspect of the work-life interface, as well as which type of resources, has a stronger effect on insomnia.

\subsection{The gendered experience of the work-life interface and sleep-related outcomes}

Current literature indicates that certain socio-demographic variables, such as gender, are predisposing factors of insomnia. Specifically, women have been found to be comparatively more predisposed to develop insomnia (Ohayon 1996, 2002). Gender also plays a role in the work-life interface. Indeed, a substantial body of evidence suggests that women, following the strength and persistence of traditional gender roles and expectations, are more likely compared to men to experience difficulties in balancing work and non-work roles and demands, which leads to relatively higher work-family conflict or poorer work-life fit (for a review see, e.g., Frone et al. 1992, 1996).

The extent to which the work-life interface may generate gender-specific sleep outcomes is somewhat contested, as evidence is mixed. Some studies have shown that work-life interference and gendered obligations are strongly associated with poorer sleep quality in females rather than males (e.g., Maume et al. 2009; 2010). Nevertheless, some research has demonstrated that work-family conflict is a relevant source of strain 
that predicts diminished sleep quality mainly for men (e. g., Magee et al. 2018). Finally, work and family responsibilities may not have any significant gendered effect on sleep habits and quality of sleep or bring about similar effects on men and women alike (e.g., Barnes et al. 2012; Lallukka et al. 2010; Van Tienoven et al. 2014). In sum, even if the adverse effects of the work-life interface on sleep have been increasingly investigated, the different effects on men and women deserve further attention. Considering all of this evidence, no formal hypothesis on gender differences is formulated (and tested) in this study. As for this issue, this study is exploratory in nature.

\section{Data and methods}

\subsection{Sample}

Analyses draw on the Swiss Household Panel, an annual panel study based on a random sample of households in Switzerland. The sample for this study consists of employees for whom complete data for all variables included in the models are available across the 2004 and 2016 waves: 40,240 person-year observations nested within 9,930 employees (20,026 observations nested within 4,842 males and 20,214 observations nested within 5,088 females). Sampled employees have been included in the sample for 4 years on average.

\subsection{Measures}

Insomnia. The respondents were asked to indicate whether, during the last 4 weeks, they experienced "difficulties in falling asleep or insomnia". This item, which was originally assessed on a 3-point scale (0 "not at all"; 1 "somewhat"; 2 "very much") was dummy-recoded (0 "not at all"; 1 "somewhat or very much"). Hence, mild or severe insomnia is the outcome variable of this study.

Work-life conflict. The work-life conflict was measured using two items, "How strongly does your work interfere with your private activities and family obligations, more than you would want?" and "How strongly are you exhausted after work to do things you would like to do?". These items, which indicated time-based and strainbased work-life conflict (Greenhaus and Beutell 1985), respectively, were assessed on a scale ranging from 0 ("not at all") to 10 ("very strongly").

Psychological detachment. Psychological detachment from work was assessed on a scale ranging from 0 ("not difficult at all") to 10 ("extremely difficult"), as follows: "How difficult do you find it to disconnect from work when the workday is over?" The item was reverse coded, so that higher values indicated recovery and recuperation processes. 


\subsection{Control variables}

We included in the models some of the most common predisposing and precipitating factors of insomnia (for a review see, e. g., Knutson 2013; Ohayon 1996, 2002). These are:

1. socio-demographic and economic variables, such as age; age squared; marital status [coded in the following categories: single/never married (reference category), married, separated/divorced, widowed]; household size; number of children in the household; educational attainment [coded in the following categories: compulsory education (reference category), apprenticeship, university entrance diploma, post-apprenticeship diploma, university degree]; Swiss citizenship [dummy recoded as follows: 0 "no" 1 "yes"]; logarithm of net total annual household income;

2. work-and employment-related variables, such as temporary employment [dummy coded as follows: 0 "no" 1 "yes"]; part-time employment [dummy coded as follows: 0 "no" 1 "yes"]; weekly working hours; private sector employment [dummy coded as follows: 0 "no" 1 "yes"]; class position [coded, using the Goldthorpe's scheme in the following categories: higher controllers (reference category), lower controllers, routine non-manual labour, manual supervisors, skilled manual workers, semi/unskilled workers, and agricultural workers]; work intensity, measured with the following item "do you have to work fast?" and assessed on a scale ranging from 0 "never" to 10 "all the time"; stress, measured with the following item "does your job expose you to an important strain?" [dummy coded as follows: 0 "no" 1 "yes"]; perceived job insecurity, measured with the following item "would you say that your job is..." and assessed by the following categories: very secure (reference category), quite secure, a bit insecure, very insecure;

3. stressful or negative life events, such as the death of a closely related person [dummy coded as follows: 0 "no" 1 "yes"]; end of a close relationship [dummy coded as follows: 0 "no" 1 "yes"]; conflict with or among closely related persons [dummy coded as follows: 0 "no" 1 "yes"];

4. health-related and lifestyle factors, such as health satisfaction, assessed on a scale ranging from 0 "not at all satisfied" to 10 "completely satisfied"; physical activity, measured with the following item "do you currently practice physical activities which make you slightly breathless" [dummy coded as follows: 0 "no" 1 "yes"];

5. satisfaction in domains of life such as job satisfaction, satisfaction with the amount of free time, and satisfaction in financial situation, which were all assessed on a scale ranging from 0 "not at all satisfied" to 10 "completely satisfied";

6. contextual factors, assessed with the following variables: survey wave [2004 (reference category) to 2016, dummy recoded]; region [Lake Geneva (reference 
category), Middleland, North-West Switzerland, Zurich, East Switzerland, Central Switzerland, Ticino].

\subsection{Models and estimation methods}

As previously discussed, the aim of this study is to estimate the effect of time- and strain-based conflict and psychological detachment from work on insomnia while controlling for observed and unobserved individual characteristics. For this scope, we applied static and dynamic logistic regression models specified as follows:

$$
y_{i t}^{*}=\beta^{\prime} x_{i t}+\alpha_{i}+\varepsilon_{i t}(i=1, \ldots, N ; t=1, \ldots T)
$$

where $y_{i t}^{*}$ denotes the latent continuous outcome of individual i on occasion $\mathrm{t}$ that determines the observed response $y_{i j}=1$ iff $y_{i j}^{*}>0$ and a value of 0 otherwise; $x_{i t}$ is a set of observed covariates associated with the outcome; $\alpha_{i}$ is the individual-specific and time-invariant unobserved heterogeneity; and $\alpha_{i}$ is the idiosyncratic error term that has variance fixed to one. We estimated this equation with different estimators: random effects (RE) and fixed effects (FE). A RE model assumes the covariates to be uncorrelated with the individual specific error term. If the individual effects correlate with the explanatory variables, RE provides biased estimates. If this assumption cannot be met, FE estimator can be considered a better choice because it yields unbiased parameter estimates by erasing time-constant unobserved heterogeneity (Cameron and Trivedi, 2009). Furthermore, in order to assess the strength of path dependence, i. e. the extent to which past experiences of insomnia determine current conditions of sleep, we used a correlated random effect approach (CRE) (see, e. g. Contoyannis et al. 2004; Mundlak 1978; Wooldridge 2005). The CRE model was specified as:

$$
y_{i t}^{*}=\gamma^{\prime} y_{i t-1}+\beta^{\prime} x_{i t}+\alpha_{i}+\varepsilon_{i t}(i=1, \ldots, N ; t=2, \ldots T)
$$

where $y_{i t-1}$ expresses the lagged values of the dependent variable and is the corresponding parameter that captures the structural path dependence, that is, the degree to which exogenous past changes in sleep quality affect the current sleep quality.

To deal with the initial conditions problem that appears when the first panel observation is not the true initial outcome of the process and to allow for the correlation between the observed covariates and the time-invariant individual specific characteristics in the sleep process, the individual effect was parametrized as follows:

$$
\alpha_{i}=\alpha_{0}+\alpha_{0}^{\prime} y_{i 1}+\alpha_{1}^{\prime} \bar{x}_{i}+u_{i}
$$

$y_{i 1}$ is the initial state, that is, the state of individual $i$ on the dependent variable at the time of the first observation and $\alpha_{0}^{\prime}$ is the corresponding parameter; $\bar{x}_{i}$ is the part of the unobserved individual heterogeneity correlated with the $\mathrm{X}_{\mathrm{it}}$ and $\alpha_{1}$ is the corresponding coefficient (Chamberlain 1982; Mundlak 1978; Wooldridge 2005). Based on differences in the work-life experience, risk exposure to insomnia and any relevant covariates between men and women, the analyses were stratified by gender. 


\section{$4 \quad$ Findings}

\subsection{Descriptive statistics}

Figure 1, Figure 2, and Figure 3 display the percentages, along with their $95 \%$ confidence intervals, of employees (i. e. person-years observations) reporting insomnia across the levels of time- and strain-based conflict, and psychological detachment from work. These reveal a clear relationship between the three work-life interface constructs and insomnia, for both male and female employees.

Figure 1 Adjusted predictions (with 95\% confidence intervals) of "timebased conflict" on insomnia (pooled sample, waves 2004 to 2016)

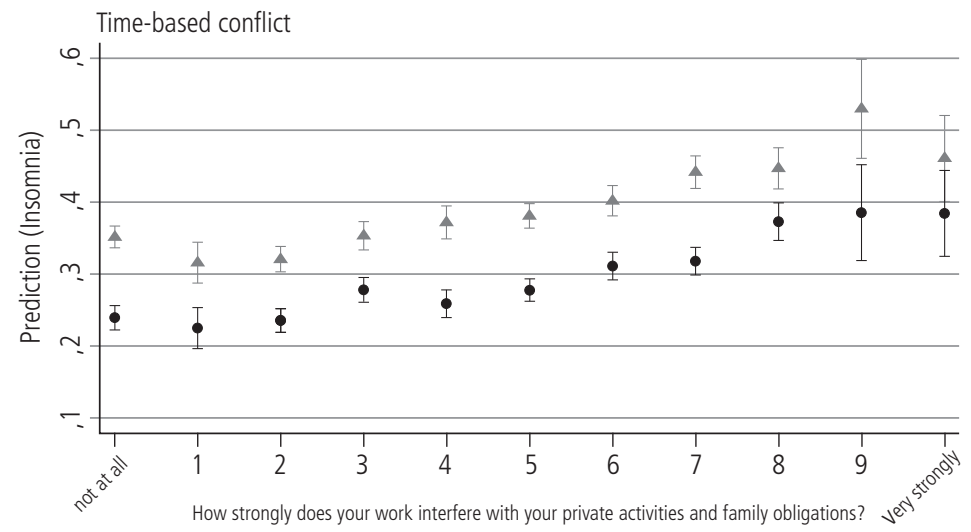

Figure 2

Adjusted predictions (with 95\% confidence intervals) of "strainbased conflict" on insomnia (pooled sample, waves 2004 to 2016)

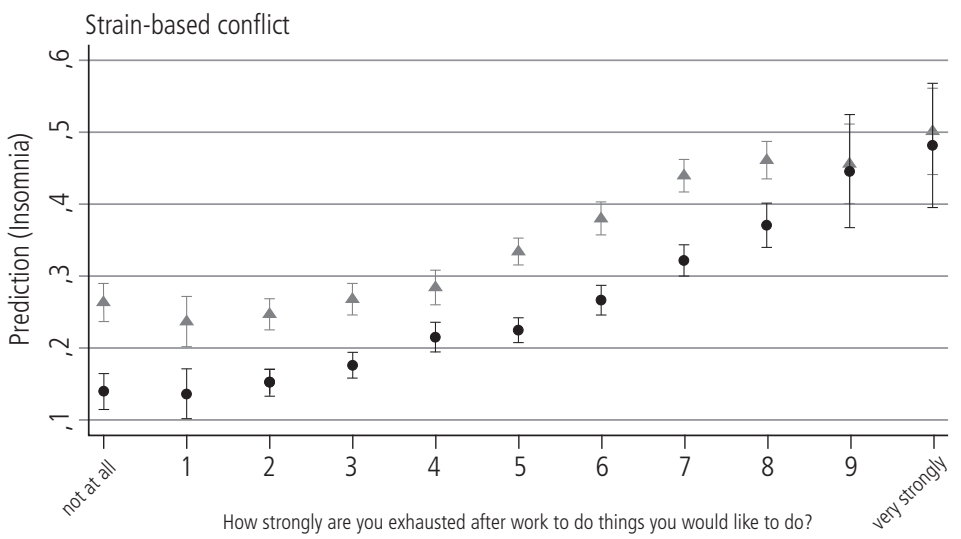


Figure $3 \quad$ Adjusted predictions (with 95\% confidence intervals) of "psychological detachment from work" on insomnia (pooled sample, waves 2004 to 2016)

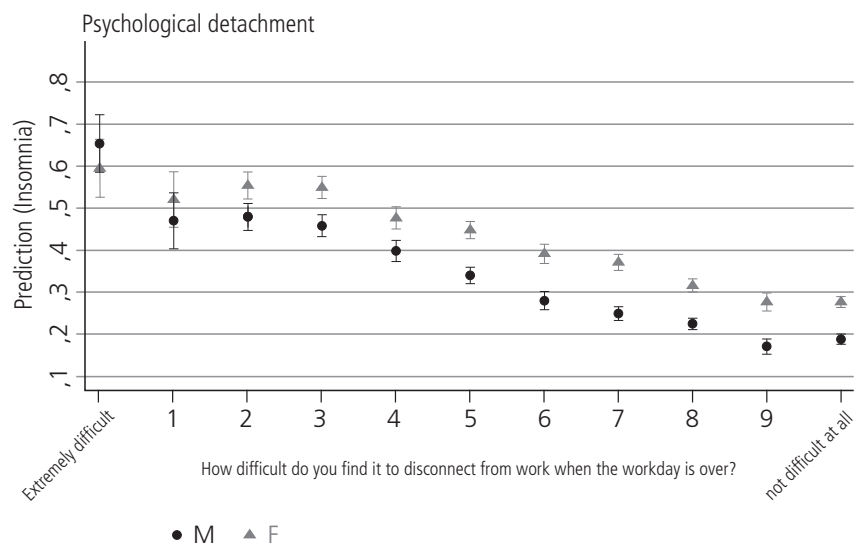

Regarding control variables (Table 1), the prevalence of insomnia ranges from $28.0 \%$ in the male sample to $37.4 \%$ in the female sample. Risk factors include, for both men and women: older age; marital status (higher prevalence in divorced/separated or widowed versus married or never married individuals); higher work intensity; stressful working conditions; perceived job insecurity; lower levels of job satisfaction, satisfaction with the amount of free time, and satisfaction in financial situation; the end of a close relationship; conflict with or among closely related persons; physical inactivity; foreign citizenship; residency in Lake Geneva region. Finally, the prevalence of insomnia has increased over the survey waves in both the male and female samples. A plausible explanation for that trend is the process of ageing of the originally sampled population of households. There are a couple of gender differences that are worth mentioning. In particular, higher socio-economic status and higher educational attainment are risk factors, but mainly for men; however, the prevalence of insomnia is higher among part-time employees, primarily in the female sample.

To illustrate the dynamic nature of insomnia, we computed empirical transition probabilities. The results indicate that about $19 \%$ of employees (i. e. person-years observations) with no reported history of insomnia at time $t_{-1}$ reported insomnia at time $t$. However, about $63 \%$ of sampled individuals (i. e. person-years observations), and namely $60.2 \%$ in the male sample and $64.4 \%$ in the female sample, that had trouble sleeping at time $t_{-1}$ reported the same condition at time $t$. In other words, a past episode of insomnia increases the likelihood of a subsequent episode 


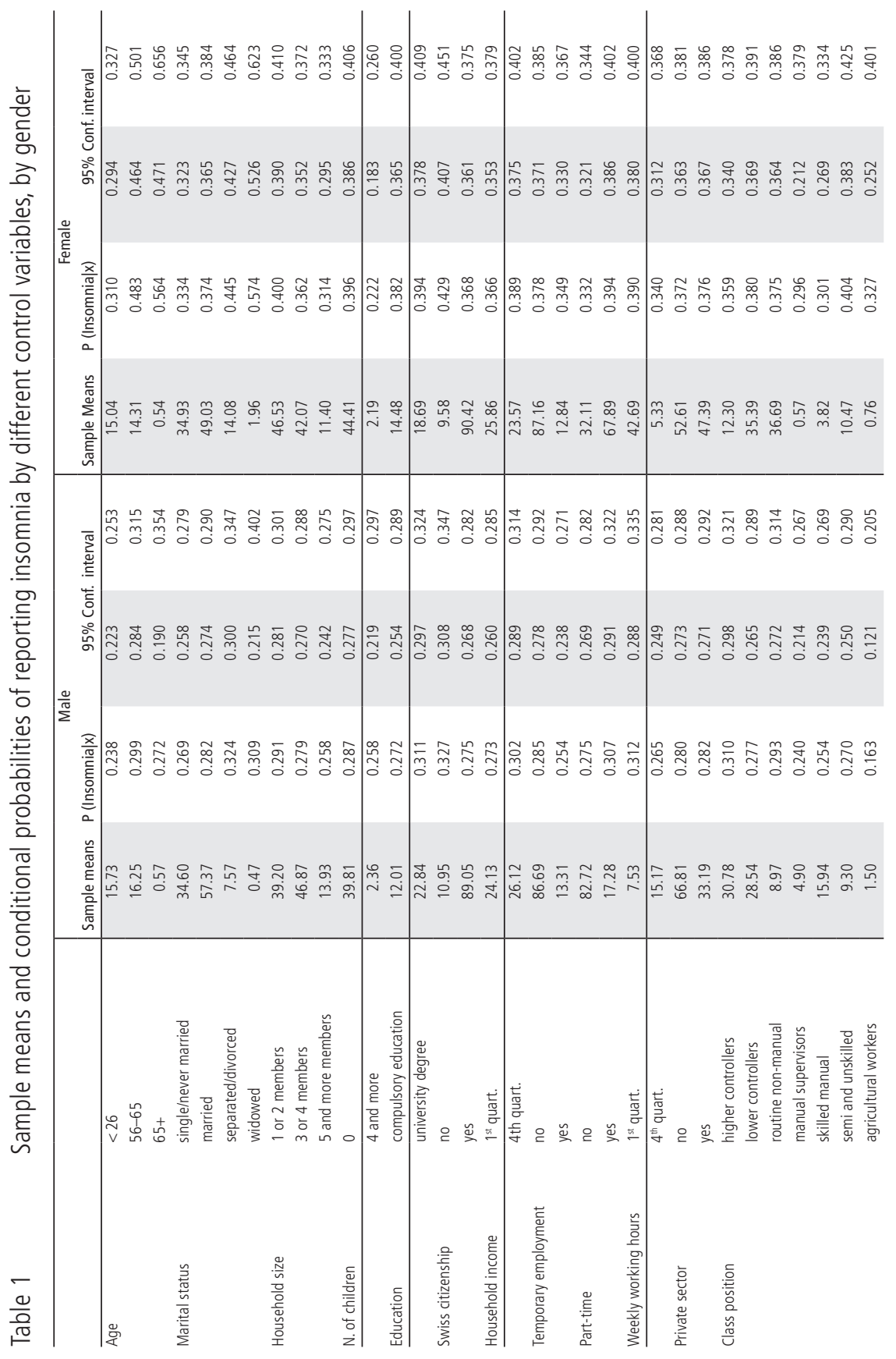




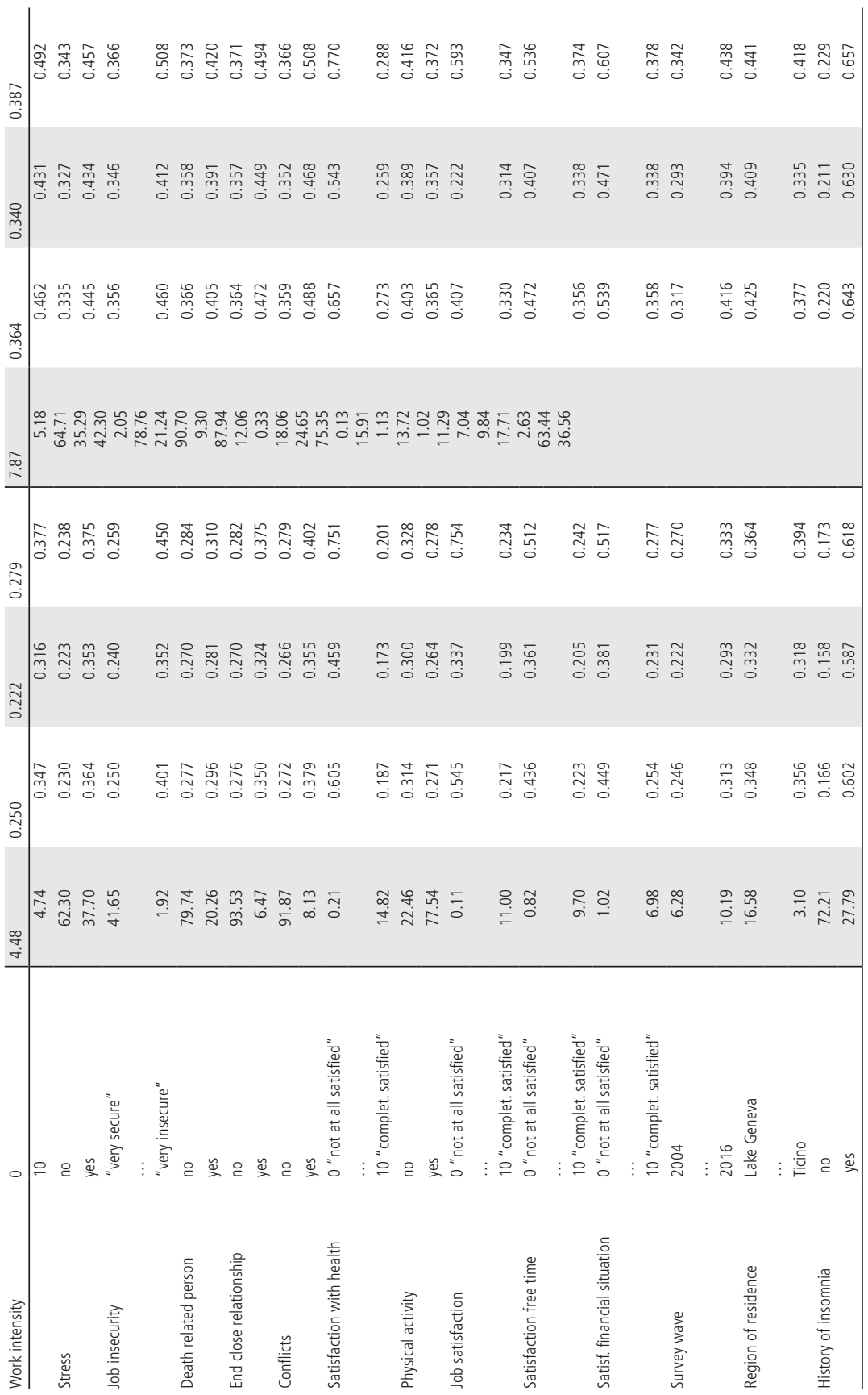


of insomnia by about 43 percentage points ( 43.4 percentage points for males and 42 for females). This is what Heckman (1981) termed as spurious (i.e. overestimated) path-dependence, that is the propensity of an individual being in a given condition (i. e., reporting insomnia) due to individual observed and unobserved heterogeneity.

\subsection{Static and dynamic logistic regression models}

To understand whether the difference between the parameters of the RE and FE estimators is systematic, we ran a Hausman model selection test. According to this test, the FE models should be preferred over the RE models. We have good reasons to believe that in the static RE specifications, time-constant unobserved characteristics are likely to correlate with the explanatory variables. Parameter estimates displayed in Table 2 show that, contrary to expectations (see hypothesis 1), this study did not find a significant effect of time-based conflict on insomnia in any model. The estimated coefficients on strain-based conflict are statistically and positively correlated with insomnia only in the static RE model, while the same parameters are not statistically significant in the FE model. Neither Hypothesis 2 is confirmed. Psychological

Table 2

Effect (logit parameters) of time- and strain-based conflict and psychological detachment from work on insomnia ( $B$ and standard errors), by gender: random effects (RE), fixed effects (FE), and correlated random effects (CRE) specifications

\begin{tabular}{|c|c|c|c|c|c|c|}
\hline & \multicolumn{2}{|c|}{$\mathrm{RE}$} & \multicolumn{2}{|c|}{$\mathrm{FE}$} & \multicolumn{2}{|c|}{ CRE } \\
\hline & M & $\mathrm{F}$ & M & $\mathrm{F}$ & M & $\mathrm{F}$ \\
\hline \multirow[t]{2}{*}{ Time-based conflict } & -0.02 & -0.003 & -0.009 & 0.003 & -0.017 & -0.003 \\
\hline & $(0.01)$ & $(0.01)$ & $(0.01)$ & $(0.01)$ & $(0.01)$ & $(0.01)$ \\
\hline \multirow[t]{2}{*}{ Strain-based conflict } & $0.034^{*}$ & $0.036^{* *}$ & 0.02 & 0.022 & 0.017 & 0.027 \\
\hline & $(0.01)$ & $(0.01)$ & $(0.02)$ & $(0.01)$ & $(0.02)$ & $(0.01)$ \\
\hline \multirow[t]{2}{*}{ Psychological detachment } & $-0.183^{* * *}$ & $-0.151^{* * *}$ & $-0.110^{* * *}$ & $-0.112^{* * *}$ & $-0.119^{* * *}$ & $-0.107^{* * *}$ \\
\hline & $(0.02)$ & $(0.003)$ & $(0.009)$ & $(0.003)$ & $(0.017)$ & $(0.003)$ \\
\hline \multirow[t]{2}{*}{ Insomnia $\left(t_{0}\right)$} & & & & & $1.676^{* * *}$ & $1.308^{* * *}$ \\
\hline & & & & & $(0.1)$ & $(0.07)$ \\
\hline \multirow[t]{2}{*}{ Insomnia $\left(t_{-}\right)$} & & & & & $0.635^{* * *}$ & $0.752^{* * *}$ \\
\hline & & & & & $(0.07)$ & $(0.06)$ \\
\hline
\end{tabular}

Hausman test (male sample) $\quad \mathrm{Chi}^{2}(44)=193.50 ;$ prob $>$ chi2 $=0.0000$

Hausman test (female sample) $\mathrm{Chi}^{2}(44)=116.84 ;$ prob $>$ chi2 $=0.0000$

${ }^{*} p<.05 ;{ }^{* *} p<.01 ;{ }^{* * *} p<.001$.

'Adjusted for: age; age squared; marital status; household size; number of children in the household; educational attainment; Swiss citizenship; logarithm of net total annual household income; temporary employment; part-time employment; weekly working hours; private sector employment; class position; work intensity; stress; perceived job insecurity; the death of a closely related person; end of a close relationship; conflict with or among closely related persons; health satisfaction; physical activity; job satisfaction. satisfaction with the amount of free time; satisfaction in financial situation; survey wave; region. 
detachment from work significantly affects insomnia in all the analytic strategies presented for both male and female employees. Hence, hypothesis 3 is confirmed.

Table 3 reports the average marginal effects for all model specifications. The results indicate that in the dynamic logistic regression models (CRE), which include the lagged dependent variable, any unit of increase in psychological detachment from work reduces the probability of experiencing insomnia by 1.5 percentage points for male employees and by 1.7 percentage points for female employees. As expected, these parameter estimates are lower than those obtained by running FE models. When comparing parameter estimates obtained in models fitting between male and female samples, we found no statistically significant difference. Hence, we may argue that the magnitude of the effect of constructs measuring work-life interface on insomnia is similar between the two groups.

Table 3

Average Marginal Effects (AME) of time- and strain-based conflict and psychological detachment from work on insomnia (derivatives of responses and standard errors), by gender: random effects (RE), fixed effects (FE), and correlated random effects (CRE) specifications

\begin{tabular}{|c|c|c|c|c|c|c|}
\hline & \multicolumn{2}{|c|}{ RE } & \multicolumn{2}{|c|}{$\mathrm{FE}$} & \multicolumn{2}{|c|}{ CRE } \\
\hline & M & $F$ & $M$ & $F$ & M & $F$ \\
\hline Time-based conflict & $\begin{array}{c}-0.003 \\
(0.002)\end{array}$ & $\begin{array}{l}-0.000 \\
(0.002)\end{array}$ & $\begin{array}{c}-0.002 \\
(0.003)\end{array}$ & $\begin{array}{c}0.000 \\
(0.002)\end{array}$ & $\begin{array}{l}-0.002 \\
(0.002)\end{array}$ & $\begin{array}{c}0.000 \\
(0.002)\end{array}$ \\
\hline Strain-based conflict & $\begin{array}{l}0.004^{*} \\
(0.002)\end{array}$ & $\begin{array}{l}0.005^{* *} \\
(0.002)\end{array}$ & $\begin{array}{c}0.004 \\
(0.003)\end{array}$ & $\begin{array}{c}0.004 \\
(0.003)\end{array}$ & $\begin{array}{c}0.002 \\
(0.002)\end{array}$ & $\begin{array}{c}0.004 \\
(0.002)\end{array}$ \\
\hline Psychological detachment & $\begin{array}{c}-0.023^{* * *} \\
(0.001)\end{array}$ & $\begin{array}{c}-0.023^{* * *} \\
(0.002)\end{array}$ & $\begin{array}{c}-0.022^{* * *} \\
(0.005)\end{array}$ & $\begin{array}{c}-0.020 * * * \\
(0.006)\end{array}$ & $\begin{array}{c}-0.015^{* * *} \\
(0.002)\end{array}$ & $\begin{array}{c}-0.017^{* *} \\
(0.002)\end{array}$ \\
\hline Insomnia (t0) & & & & & $\begin{array}{l}0.250 * * * \\
(0.01)\end{array}$ & $\begin{array}{l}0.225^{* * *} \\
(0.01)\end{array}$ \\
\hline Insomnia (t-1) & & & & & $\begin{array}{l}0.086^{* * *} \\
(0.01)\end{array}$ & $\begin{array}{c}0.125^{* * *} \\
(0.011)\end{array}$ \\
\hline
\end{tabular}

${ }^{*} p<.05 ;{ }^{* *} p<.01 ;{ }^{* * *} p<.001$.

${ }^{1}$ Adjusted for: age; age squared; marital status; household size; number of children in the household; educational attainment; Swiss citizenship; logarithm of net total annual household income; temporary employment; part-time employment; weekly working hours; private sector employment; class position; work intensity; stress; perceived job insecurity; the death of a closely related person; end of a close relationship; conflict with or among closely related persons; health satisfaction; physical activity; job satisfaction. satisfaction with the amount of free time; satisfaction in financial situation; survey wave; region.

The results also suggest a certain degree of persistence of insomnia when accounting for individual-specific heterogeneity. More in detail, the likelihood of developing insomnia is 8.6 percentage points higher in male employees who had a past insomnia complaint compared to those who did not and 12.5 percentage points higher in female employees with a past episode of insomnia compared to those who reported 
a better sleep quality. As expected, the magnitude of these parameters, which measure structural path dependence, is much lower compared to the size of empirical transition probabilities, i. e., spurious path dependence. The strength of structural path dependence parameters reflects the effect of behavioural, attitudinal and physiological changes caused by a reported history of insomnia (see, e. g., Attarian 2017; Levenson et al. 2015).

\section{Discussion and conclusion}

Previous studies have indicated that insomnia is a common health issue, which is associated with a range of adverse consequences in different domains of life (Attarian 2017; Crain et al. 2014; Hammig et al. 2009; Kessler et al. 2011; Mullins et al. 2014; Pilcher and Huffcutt 1996; Sarsour et al. 2011). Hence, in an attempt to promote well-being and productivity at work and reduce associated health care costs, treating insomnia is a major concern, for both employers and national governments.

There have been several calls for further research in the field of social sciences to shed more light on the determinants of insomnia and other sleep problems or disorders, while properly assessing the magnitude of the effect of the work-life interface (e.g., Gisler et al. 2018; Grzywacz 2016). To respond to such calls, we used data from the Swiss Household Panel and investigated whether and to what extent work-life conflict - decomposed into time- and strain- based conflicts (Greenhaus and Beutell, 1985) - and the ability to disconnect mentally from work (i. e. psychological detachment from work) (Etzion et al. 1998; Fritz and Sonnentag 2006) affect sleep initiation and maintenance problems. In an attempt to extend prior research, we employed static and dynamic panel data methods and determined the unique contribution of these three work-life constructs to the prediction of insomnia, while controlling for a wide range of predisposing and precipitating factors (Spielman 1986; Spielman et al. 1987) and for the strength of path-dependence (Heckman 1981) in sleep patterns.

In summary, the findings confirm that work-life conflict and low psychological detachment from work may deplete key resources such as time and therefore human energy, which, in turn, may cause difficulties initiating or maintaining sleep (e.g. Crain et al. 2018). However, when adequately accounting, by means of a complex research design, for individual heterogeneity and for the relative importance of multiple contributing factors, recovery and recuperation processes from/after work appear crucial to the experience of insomnia, while the significance of perceived work-life conflict recede. In practice, as for the effect of the work-life interface, which was the focus of this study, primary triggers of insomnia relate to emotional involvement in and rumination about work-related issues during off-job time; conversely, time constraints and job strain do not result in the same detrimental outcomes. Hence, 
there is reason to believe that both person- and organisation-directed interventions aimed at reducing work-related thoughts and cognitive arousal - such as cognitive behavioural training, counselling, relaxation exercises, mindfulness meditation, social support, work process restructuring, performance appraisals - could be more effective in addressing employee sleep onset and maintenance problems. That said, as suggested by the 3P behavioural model (Spielman et al. 1987), insomnia is best understood as resulting from a variety of genetic, psychological, behavioural, socio-economic, and contextual factors. In this regard, the findings show that the magnitude a previous episode of insomnia or negative or stressful life events have a much higher effect on insomnia compared to the experiences of the work-life interface.

Finally, estimated parameters are quite similar in the male and female samples, indicating that apparently, gender differences in the effect of the work-life interface on sleep quality are not significant. Overall, these findings are consistent with those of van Tienoven and colleagues (2014), who found that increasing work and family responsibility do not seem to result in alteration of the circadian or homeostatic aspects of the sleep process, but rather predict regular timing of sleep and sleep habits, for both men and women.

Despite these novel and empirically sound findings, which only partially support the previous cross-sectional research on the adverse effects of the gendered character of the work and non-work experiences on sleep, this study has some limitations that need to be acknowledged. In particular, the outcome variable was a self-reported measure of sleep. Therefore, the reports may have been biased. Indeed, subjective reports of sleep quality tend to be lower compared to objective sleep measures derived from actigraphy or polysomnography (e.g., Edinger and Krystal 2003). In addition, because of gendered cultural frameworks, men may be less inclined to admit sleep complaints (Knutson 2013; van den Berg et al. 2009). Nonetheless, we trust that this study opens the way for more research that could investigate the causal effect of the work-nonwork interface on sleep using longitudinal data and techniques that are more rigorous.

\section{References}

Allen, Tammy D., and Lillian T. Eby (eds.). 2016. The Oxford Handbook of Work and Family, New York: Oxford University Press.

Allen, Tammy D., David E. Herst, Carly S. Bruck, and Martha Sutton. 2000. Consequences Associated with Work-to-family Conflict: A Review and Agenda for Future Research. Journal of Occupational Health Psychology 5: 278-308.

Attarian, Hrayr P. (ed). 2017. Clinical Handbook on Insomnia. New York: Springer.

Barnes, Christopher M., David T. Wagner, and Sonia Ghumman. 2012. Borrowing from Sleep to Pay Work and Family: Expanding Time-Based Conflict to the Broader Nonwork Domain. Personnel Psychology 65: 789-819. 
Berkman Lisa F., Sze Yan Liu, Leslie Hammer, Phyllis Moen, Laura Cousino Klein, Erin Kelly, Martha Fay, Kelly Davis, Mary Durham, Georgia Karuntzos, and Orfeu M. Buxton. 2015. Work-family Conflict, Cardiometabolic Risk, and Sleep Duration in Nursing Employees. Journal of Occupational Health Psychology 20(4): 420-433.

Buxton, Orfeu M., Soomi Lee, Chloe Beverly, Lisa F. Berkman, Phyllis Moen, Erin L. Kelly, Leslie B., Hammer, and David M. Almeida. 2016. Work-family Conflict and Employee Sleep: Evidence from IT workers in the Work, Family and Health Study. Sleep 39(10): 1911-1918.

Cameron, Adrian C. and Pravin K. Trivedi. 2009. Microeconometrics using Stata. College Station, Texas: Stata Press.

Chamberlain, Gary. 1982. Multivariate Regression Models for Panel Data. Journal of Econometrics 1: 5-46.

Contoyannis, Paul, Andrew M. Jones and Nigel Rice. 2004. The Dynamics of Health in the British Household Panel Survey. Journal of Applied Econometrics 19: 473-503.

Crain, Tori L., Rebecca M. Brossoit and Gwenith G. Fisher. 2018. Work, Nonwork, and Sleep (WNS): A Review and Conceptual Framework. Journal of Business Psychology 33, 675-697.

Crain, Tori L., Leslie B. Hammer, Todd Bodner, Ellen Ernst Kossek, Phyllis Moen, Richard Lilienthal and Orfeu M. Buxton. 2014. Work-family Conflict, Family-supportive Supervisor Behaviors, and Sleep Outcomes. Journal of Occupational Health Psychology 19(2): 155-167.

Cropley Mark and Fred Zijlstra. 2011. Work and Rumination. Pp. 487-503 in Handbook of Stress in the Occupations, edited by Janice Langan-Fox and Cary L. Cooper C. Cheltenham, PA: Edward Elgar Publishing.

Edinger, Jack D., and Andrew D. Krystal. 2003. Subtyping Primary Insomnia: Is Sleep State Misperception a Distinct Clinical Entity? Sleep Medicine Reviews 7(3): 203-214.

Edwards, Jeffrey R., and Nancy P. Rothbard. 2000. Mechanisms Linking Work and Family: Clarifying the Relationship between Work and Family Constructs. Academy of Management Review 25: 178-199.

Etzion, Dalia, Dove Eden, and Yael Lapidot. 1998. Relief from Job Dtressors and Burnout: Reserve Service as a Respite. Journal of Applied Psychology 83: 577-585.

Fritz, Charlotte, and Sabine Sonnentag. 2006. Recovery, wWell-being, and Performance-related Outcomes: The Role of Workload and Vacation Experiences. Journal of Applied Psychology 91: 936-945.

Frone Michael R., Marcia Russell, and Grace M. Barnes. 1996. Work-family Conflict, Gender, and Health-related Outcomes: A Study of Employed Parents in two Community Samples. Journal of Occupational Health Psychology 1: 57-69.

Frone Michael R., Marcia Russell, and M. Lynne Cooper. 1992. Prevalence of Work-family Conflict: Are Work and Family Boundaries Asymmetrically Permeable? Journal of Organizational Behavior 13: 723-729.

Frone, Michael R. 2003. Work-family Balance. Pp. 143-162 in Handbook of Occupational Health Psychology, edited by James C. Quick, and Louis Tetrick. Washington, DC: American Psychological Association.

Gisler, Stefanie, Rachel Omansky, Paige R. Alenick, Alexandra M. Tumminia, Erin M. Eatough, and Ryan C. Johnson. 2018. Work-life Conflict and Employee Health: A Review. Journal of Applied Biobehavioral Research 23(4): e12157.

Greenhaus, Jeffrey H., and Nicholas J. Beutell. 1985. Sources of Conflict Between Work and Family Roles. Academy of Management Review 10: 76-88.

Greenhaus, Jeffrey H., Tammy D. Allen, and Paul E. Spector. 2006. Health Consequences of Work-Family Conflict: The Dark Side of the Work-family Interface. Pp. 61-98 in Research in Occupational Stress and Well-being (Vol. 5), edited by Pamela L. Perrewe, and Daniel C. Ganster. Amsterdam, the Netherlands: JAI Press/Elsevier.

Grzywacz, Joseph G. 2016. Work, Family and Employee Health. Pp. 389-400, in The Oxford Handbook of Work and Family, edited by Tammy D. Allen, and Lillian T. Eby. New York: Oxford University Press. 
Hammig, Oliver, and Georg Bauer. 2009. Work-life Imbalance and Mental Health among Male and Female Employees in Switzerland. International Journal of Public Health 54: 88-95.

Hammig, Oliver, Felix Gutzwiller, and Georg Bauer. 2009. Work-life Conflict and Associations with Work- and Nonwork-related Factors and with Physical and Mental Health Outcomes: A Nationally Representative Cross-sectional Study in Switzerland. Bmc Public Health 9: 435-450.

Heckman, James J. 1981. Heterogeneity and State Dependence. Pp. 91-140 in Studies in Labor Markets, edited by Sherwin Rosen. Chicago: University of Chicago Press.

Jacobsen, Henrik B., Silje E. Reme, Grace Sembajwe, Karen Hopcia, Anne M. Stoddard, Christopher T. Kenwood, Tore Stiles, Glorian Sorensen, Orfeu M. Buxton. 2014. Work-family Conflict, Psychological Distress, and Sleep Deficiency among Patient Care Workers. Workplace Health \& Safety 62: 282-291.

Kalimo, Raija, Leena Tenkanen, Mikko Härmä, Esko Poppius, and Pertti Heinsalmi. 2000. Job stress and sleep disorders: Findings from the Helsinki Heart Study. Stress Medicine 16: 65-75.

Kalmbach David A., Andrea S. Cuamatzi-Castelan, Christine V. Tonnu, Kieulinh Michelle Tran, Jason R. Anderson, Thomas Roth and Christopher L. Drake. 2018. Hyperarousal and Sleep Reactivity in Insomnia: Current Insight. Nature and Science of Sleep 10: 193-201.

Kessler, Ronald C., Patricia A. Berglund, Catherine Coulouvrat, Goeran Hajak, Thomas Roth, Victoria Shahly, Alicia C. Shillington, Judith J. Stephenson, and James K. Walsh. 2011. Insomnia and the Performance of US Workers: Results from the America Insomnia Survey. Sleep 34(9): 1161-1171.

Knutson, Kristen L. 2013. Sociodemographic and Cultural Determinants of Sleep Deficiency: Implications for Cardiometabolic Disease Risk. Social Science \& Medicine 79:7-15.

Lallukka, Tea, J.E. Ferrie, Mika Kivimäki, M.J. Shipley, M. Sekine, T. Tatsuse, Olli Pietiläinen, Ossi Rahkonen, M.G. Marmot, and Eero Lahelma. 2014. Conflicts between Work and Family Life and Subsequent Sleep Problems among Employees from Finland, Britain, and Japan. International Journal of Behavioral Medicine 21(2): 310-318.

Lallukka, Tea, Ossi Rahkonen, Eero Lahelma, and Sara Arber. 2010. Sleep Complaints in Middle-aged Women and Men: The Contribution of Working Conditions and Work-family Conflicts. The Journal of Sleep Research 19: 466-477.

Levenson, Jessica C., Daniel B. Kay, and Daniel J. Buysse. 2015. The Pathophysiology of Insomnia. Chest 147(4): 1179-1192.

Magee, Christopher A., Laura D. Robinson, and Alisha McGregor. 2018. The Work-Family Interface and Sleep Quality. Behavioral Sleep Medicine 16(6): 601-610.

Maume, David J., Rachel A. Sebastian, and Anthony R. Bardo. 2009. Gender Differences in Sleep Disruption among Retail Food Workers. American Sociological Review 74(6): 989-1007.

Maume, David J., Rachel A. Sebastian, and Anthony R. Bardo. 2010. Gender, Work-Family Responsibilities, and Sleep. Gender \& Society 24(6): 746-768.

Meier, Laurenz L., Eunae Cho, and Soner Dumani. 2016. The Effect of Positive Work Reflection during Leisure Time on Affective Well-being: Results from three Diary Studies. Journal of Organizational Behaviour 37:255-278.

Moen, Phyllis, Wen Fan, and Erin L. Kelly. 2013. Team-level Flexibility, Work-home Spillover, and Health Behavior. Social Science \& Medicine: 84: 69-79.

Mullins, Heather M., Jose M. Cortina, Christopher L. Drake, and Reeshad S. Dalal. 2014. Sleepiness at Work: A Review and Framework of how the Physiology of Sleepiness Impacts the Workplace. Journal of Applied Psychology 99(6): 1096-1112.

Mundlak, Yair 1978. On the Pooling of Time Series and Cross Section Data. Econometrica 46: 69-85.

Ohayon, Maurice. 1996. Epidemiological Study on Insomnia in the General Population. Sleep. 19 Suppl 3: 7-15. 
Ohayon, Maurice. 2002. Epidemiology of Insomnia: What we Know and What we still Need to Learn. Sleep Medicine Reviews. 6(2): 97-111.

Perlis, Michael, Paul J. Shaw, Georgina Cano, and Colin A. Espie. 2011. Models of Insomnia. Pp. 850-865 in Principles and Practices of Sleep Medicine, edited by Meir Kryger, Thomas Roth and William Dement. St. Louis: Elsevier.

Pilcher, June J., and Allen Huffcutt. 1996. Effects of Sleep Deprivation on Performance: A Meta-analysis. Sleep 19: 318-326.

Sarsour, Khaled, Anupama Kalsekar, Ralph Swindle, Kathleen Foley, and James K. Walsh. 2011. The Association between Insomnia Severity and Healthcare and Productivity Costs in a Health Plan Sample. Sleep 34(4): 443-450.

Quinn, Ryan W., Gretchen M. Spreitzer and Chak Fu Lam. 2012. Building a Sustainable Model of Human Energy in Organizations: Exploring the Critical Role of Resources. Academy of Management Annals 6(1), 337-396.

Sekine, Michikazu, Tarani Chandola, Pekka Martikainen, Michael Marmot, and Sadanobu Kagamimori. 2006. Work and Family Characteristics as Determinants of Socioeconomic and Sex Inequalities in Sleep: The Japanese Civil Servants Study. Sleep 29(2): 206-216.

Shockley, Kristen M., Winny Shen, and Ryan C. Johnson (eds.). 2018. The Cambridge Handbook of the Global Work-Family Interface. Cambridge: Cambridge University Press.

Sonnentag, Sabine, Iris Kuttler, and Charlotte Fritz. 2010. Job Stressors, Emotional Exhaustion, and Need for Recovery: A Multi-source Study on the Benefits of Psychological Detachment. Journal of Vocational Behavior 76: 355-365.

Sonnentag, Sabine. 2001. Work, Recovery Activities, and Individual Well-being: A Diary Study. Journal of Occupational Health Psychology 6(3):196-210.

Spielman, Arthur J. 1986 Assessment of Insomnia. Clinical Psychological Review 6: 11-26.

Spielman, Arthur J., Lauren S. Caruso, and Paul B. Glovinsky. 1987. A Behavioral Perspective on Insomnia Treatment. Psychiatric Clinics of North America 10: 541-553.

van den Berg Julia F., Henk M. Miedema, Joke H. Tulen, Albert Hofman, Arie K. Neven, and Henning Tiemeier. 2009. Sex Differences in Subjective and Actigraphic Sleep Measures: A Population-based Study of Elderly Persons. Sleep 32: 1367-1375.

van Tienoven, Theun, Ignace Glorieux, and Joeri Minnen. 2014. The Impact of Work and Family Responsibilities on Healthy Sleep Habits. Time \& Society 23(2): 235-257.

Vedaa, Øyesten, Elfrid Krossbakken, Ingse D. Grimsrud, Bjørn Bjorvatn, Børge Sivertsen, Nils Magerøy, Stale Einarsen, and Stale Pallesen. 2016. Prospective Study of Predictors and Consequences of Insomnia: Personality, Lifestyle, Mental Health and Work-related Stressors. Sleep Medicine 20: 1-29.

Wooldridge, Jeffrey M. 2005. Simple Solutions to the Initial Conditions Problem in Dynamic, Nonlinear Panel Data Models with Unobserved Heterogeneity. Journal of Applied Econometrics 20: 39-54. 